\title{
Corrigendum: Nanocrystalline diamond surfaces for adhesion and growth of primary neurons, conflicting results and rational explanation
}

\section{Matthew McDonald*}

Institute for Materials Research in MicroElectronics (IMO-MEC), Hasselt University, Diepenbeek, Belgium

${ }^{*}$ Correspondence: matthew.mcdonald@uhasselt.be

Edited and reviewed by:

Laura Ballerini, University of Trieste, Italy

Keywords: nanocrystalline diamonds, corrigendum, adhesion, growth, neurons

\section{A commentary on}

Nanocrystalline diamond surfaces for adhesion and growth of primary neurons, conflicting results and rational explanation

by Ojovan, S. M., McDonald, M., Rabieh, N., Shmuel, N., Erez, H., Nesladek, M., and Spira, M. E. (2014). Front. Neuroeng. 7:17. doi: 10.3389/fneng.2014.00017

The article "Nanocrystalline diamond surfaces for adhesion and growth of primary neurons, conflicting results and rational explanation," published 11 June
2014, with myself as the second author has a mispelling of my name. It came to my attention through a friend that my name is spelled incorrectly, which I did not notice during the review process.

On the paper, currently my name is spelled as: Mathew McDonald. The correct spelling is: Matthew McDonald.

Conflict of Interest Statement: The author declares that the research was conducted in the absence of any commercial or financial relationships that could be construed as a potential conflict of interest.
Received: 29 July 2014; accepted: 29 August 2014; published online: 18 September 2014.

Citation: McDonald M (2014) Corrigendum: Nanocrystalline diamond surfaces for adhesion and growth of primary neurons, conflicting results and rational explanation. Front. Neuroeng. 7:37. doi: 10.3389/ fneng.2014.00037

This article was submitted to the journal Frontiers in Neuroengineering.

Copyright (c) 2014 McDonald. This is an open-access article distributed under the terms of the Creative Commons Attribution License (CC BY). The use, distribution or reproduction in other forums is permitted, provided the original author(s) or licensor are credited and that the original publication in this journal is cited, in accordance with accepted academic practice. No use, distribution or reproduction is permitted which does not comply with these terms. 